\title{
Influence of Composition and Preparation Method on the Continuous Performance of Sn-Beta for Glucose-Fructose Isomerisation
}

\author{
Luca Botti ${ }^{1} \cdot$ Ricardo Navar $^{1} \cdot$ Søren Tolborg ${ }^{2} \cdot$ Juan S. Martinez-Espin $^{2} \cdot$ Daniele Padovan $^{1} \cdot$ Esben Taarning $^{2}$. \\ Ceri Hammond ${ }^{1}$
}

(C) The Author(s) 2018

\begin{abstract}
The stability, activity and selectivity of various Sn-Beta catalysts are investigated to identify how the composition of the catalyst, in addition to its method of preparation, impact its ability to continuously isomerise glucose to fructose. Increasing the Sn loading in post-synthetically prepared catalysts leads to a decrease of both activity and stability. Accordingly, materials containing dilute amounts of Sn appear to be most suitable for continuous operation. Furthermore, the method of preparation has a profound impact on the overall performance of the catalyst. In fact, preparation of Sn-Beta by hydrothermal synthesis results in improvements of both activity and stability, with respect to the post-synthetic preparation of an otherwise-analogous material. The improved resistance of hydrothermal Sn-Beta is attributed, through a combination of operando UV-Vis, TPD-MS and vapour adsorption isotherms, to its greater resistance to deactivation by methanol (the reaction solvent). Complementary ${ }^{119}$ Sn CPMG MAS NMR experiments also indicate the presence of different Sn sites in the hydrothermal material, which, alongside the presence of a less adsorptive siliceous matrix, may be intrinsically less prone to solvent interaction than those present in post-synthetic Sn-Beta.
\end{abstract}

Keywords Sugar conversion $\cdot$ Continuous flow $\cdot$ Glucose $\cdot$ Renewables $\cdot$ Sn-Beta $\cdot$ Zeolites

\section{Introduction}

With fossil fuel depletion becoming ever greater, researchers are increasingly focusing their efforts on sustainability. Within this area, one of the major targets is the search for alternative sources of carbon for chemical production. In this context, renewable carbon resources, such as cellulosic biomass, may provide a solution [1-3]. Cellulose is a biopolymer constituted by a chain of glucose monomers. Once depolymerised into its constituent units, it can subsequently be converted into higher value commodity compounds, some

Electronic supplementary material The online version of this article (https://doi.org/10.1007/s11244-018-1078-z) contains supplementary material, which is available to authorized users.

Ceri Hammond

hammondc4@cardiff.ac.uk

http://blogs.cardiff.ac.uk/hammond/

1 Cardiff Catalysis Institute, School of Chemistry, Cardiff University, Park Place, Cardiff CF10 3AT, UK

2 Haldor Topsøe A/S, Sustainable Chemicals, Haldor Topsøes Allé 1, 2800 Lyngby, Denmark notable examples including 5-(hydroxymethyl)furfural [4], methyl lactate [5] and methyl vinyl glycolate [6]. Whilst its significant stability makes the direct conversion of glucose into 5-(hydroxymethyl)furfural and methyl lactate challenging, its isomer, fructose, can readily be converted into them. As such, the catalytic isomerisation of glucose to fructose represents a key step in the production of cellulose-derived chemicals.

At present, glucose isomerisation is achieved through enzymatic catalysis. However, although the bio-catalytic route is highly selective, it requires strict operational conditions, leading to a process with a low degree of flexibility. As such, the development of a solid catalyst capable of performing this reaction via heterogeneous catalytic methods in a scalable manner is highly desirable [7-9]. Amongst various solid catalysts capable of performing the glucose isomerisation reaction, the zeolite Sn-Beta has been shown to be one of the most promising materials. Furthermore, Sn-Beta has also been shown to be exceptionally active for the related conversion of hexoses to methyl lactate and methyl vinyl glycolate through retro-aldol chemistry. The outstanding catalytic ability of Sn-Beta for carbohydrate valorisation has 
sparked interest for its possible utilisation on commercial scale. However, despite its excellent catalytic performance for glucose isomerisation $[10,11]$ and methyl lactate production $[12,13]$, until recently little information on its stability was available, even though the lifetime of a catalyst represents one of its most important features [14-16]. In fact, only recently have researchers started to investigate the stability of this catalyst for the continuous isomerisation of sugarbased molecules [17].

Recently, we demonstrated that Sn-Beta catalysts prepared by post-synthetic methods (solid state incorporation (SSI)) and containing Sn loadings of 2 and $10 \mathrm{wt} \%$, were capable of catalysing the continuous isomerisation of glucose to fructose, and the continuous retro-aldol fragmentation of fructose to methyl lactate, with excellent levels of stability for periods of up to 60 days. However, achieving this level of performance required optimisation of the reaction conditions, and particularly the choice of solvent. In fact, acceptable levels of continuous performance could only be achieved when small amounts of water (1-10 wt \%) were added to the traditional methanol $(\mathrm{MeOH}) /$ glucose reaction feed [18], despite water itself being a very poor reaction solvent [19]. Notably, the use of small quantities of water has also been shown to be beneficial during methyl lactate production, as it favours hydrolysis of unreactive methyl fructosides into fructose, which is then able to undergo to retroaldol cleavage [20]. After a detailed investigation employing a variety of kinetic and spectroscopic experiments, it was found that the main role of water in mitigating the deactivation of Sn-Beta during glucose conversion was to preserve the hydrated environment surrounding the active Sn sites [21]. In fact, in the absence of water i.e. when glucose isomerisation was performed in pure $\mathrm{MeOH}$, deactivation of the catalyst occurred through loss of the active $\mathrm{Sn}-\mathrm{OH}$ sites of the catalyst, via re-condensation of the framework (reformation of $\mathrm{Sn}-\mathrm{O}-\mathrm{Si}$ bonds), and alkoxylation of the active sites (Sn-OR formation). Notably, this mechanism of deactivation could be attributed solely to the negative influence of pure $\mathrm{MeOH}$. However, whilst the addition of some water mitigates this particular mechanism of deactivation, large volumes of water can impact several downstream processes, particularly separation. Hence, identifying and developing Sn-Beta catalysts more resistant to interaction with $\mathrm{MeOH}$ represents an important task.

With respect to improving the intrinsic stability of SnBeta, several parameters can influence its lifetime, and many of these have not yet been explored. In particular, the loading of $\mathrm{Sn}$ in the catalyst (directly influencing the type and distribution of the active sites), and the precise synthetic methodology employed for its synthesis (influencing the active site speciation and the general properties of the siliceous matrix), could both have a profound impact on the resistance of the catalyst toward deactivation. In fact, previous research has shown that different Sn-Beta synthetic methods lead to a different distribution of Sn species within the Beta framework, as indicated by ${ }^{119}$ Sn MAS NMR spectroscopy [22]. Similarly, different Sn loadings can also lead to different $\mathrm{Sn}$ speciation in the lattice. For example, we previously demonstrated that high metal loadings ( $>5 \mathrm{wt} \%$ ) favour the formation of extra-framework $\mathrm{SnO}_{\mathrm{x}}$ species [23]. It is thus clear that the choice of synthetic methodology, alongside the metal content of the catalyst, play a crucial role in the speciation of the active sites, eventually reflecting in different catalytic behaviour. However, the impact of these parameters on the stability of Sn-Beta during continuous operation has not yet been investigated.

Thus, the aim of this work is to gain a better understanding of how the choice of Sn loading, alongside the choice of zeolite synthesis method, influence the activity and stability of Sn-Beta for the continuous valorisation of glucose. To achieve this, a series of post-synthetic Sn-Beta catalysts containing different metal loadings are prepared by SSI $[24,25]$. Furthermore, comparison is made between analogous Sn-Beta samples prepared by hydrothermal synthesis and SSI. This range of samples permits parameters such as activity, selectivity and stability to be calculated for each material, allowing detailed insight regarding which Sn-Beta materials possess the highest levels of intrinsic stability for the continuous conversion of glucose. To generate structure-activity-lifetime relationships, and hence rationalise the observed kinetic trends, stdies with a variety of characterisation methodologies, including ${ }^{119} \mathrm{Sn}$ Carr-Purcell-MeiboomGill (CPMG) MAS NMR, operando UV-Vis, Temperature Programmed Desorption-Mass Spectrometry (TPD-MS), porosimetry, powder X-Ray Diffraction (pXRD), and vapour adsorption isotherms are also presented.

\section{Results and Discussion}

\subsection{Effect of Metal Loading of Post-synthetic Materials}

In order to investigate how the metal loading affects the activity and stability of Sn-Beta for glucose isomerisation, Sn-Beta catalysts with four different metal loadings (1, 2, 5 and $10 \mathrm{wt} \%$ ) were synthesised by SSI, following the procedure described previously [24]. XRD analysis (Fig. S1) confirms that the crystallinity of the material does not substantially change even when elevated loadings of Sn are employed, and that all catalysts possess comparable crystallinity to that of the aluminated precursor material. However, porosimetry measurements on the sample series reveal a small but steady decrease in specific surface area and micropore volume as the loading of Sn increases (Table S1).

${ }^{119} \mathrm{Sn}$ MAS NMR is the technique that has shown to be the 
most effective for characterising Sn sites in zeolites, as it is able to distinguish between framework and extra-framework Sn species [26, 27]. During recent years, much effort has been made in order to improve the typically low signal-tonoise ratio, with the recent application of a CPMG sequence by Ivanova and co-workers greatly improved this parameter [28-30]. Thus, ${ }^{119}$ Sn CPMG MAS NMR was employed to study how the Sn distribution changes as the loading of the metal increases beyond $2 \mathrm{wt} \%$ Sn (Fig. 1). We note that the acquisition time for each measurement was adjusted according to the amount of Sn present, so that comparable total signal was achieved in each case.

As can be seen, a similar distribution of $\mathrm{Sn}$ is observed for 2 and 5Sn-Beta, with two major resonances centred at -600 and $-700 \mathrm{ppm}$ observed, the final of which is by far the most dominant. These resonances are indicative of extra-framework $\mathrm{Sn}$ (both oligomeric and oxidic, henceforth denoted $\mathrm{SnOx}$ ) and hexa-coordinated framework $\mathrm{Sn}$ i.e. hydrated $\mathrm{Sn}$ isomorphously substituted into the lattice, respectively. In contrast, a clear difference in the Sn site distribution of 10Sn-Beta is observed. The signal of $\mathrm{SnOx}$ is still present, but its intensity is higher, indicating that a larger fraction of $\mathrm{SnOx}$ is present at the highest loading. Furthermore, the resonance at $-690 \mathrm{ppm}$ is no longer observed, with two signals, located at -710 and $-660 \mathrm{ppm}$, instead present. Although both signals are present in the region of chemical shift associated with hydrated framework Sn, the differences in chemical shift indicate that the active sites present at the highest loading are somewhat different to those at the lowest loadings. We note that Wolf et al. previously observed Sn site heterogeneity for a large number of Sn-Beta samples prepared by different synthetic methodologies, and attributed this to changes in the T site distribution of $\mathrm{Sn}[31$,

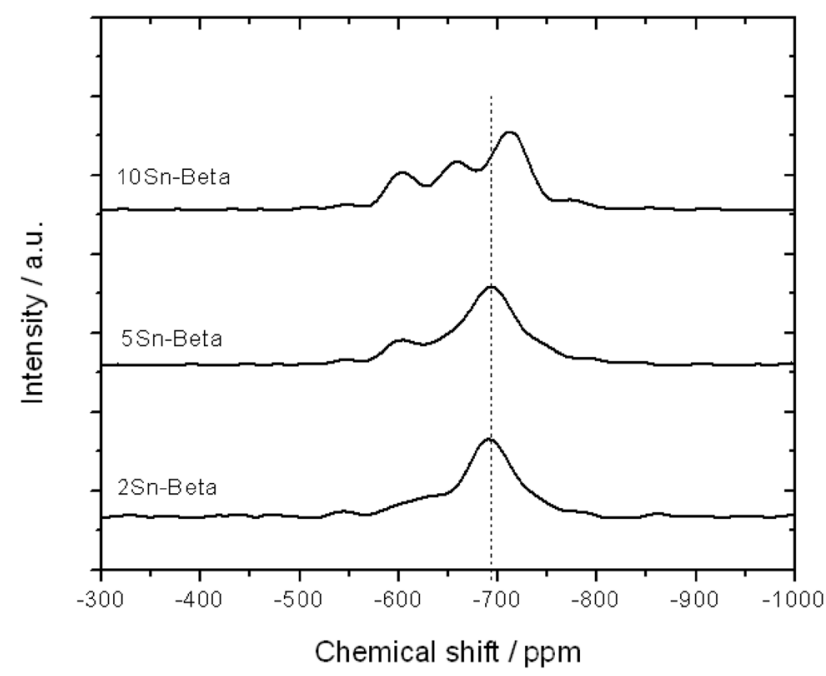

Fig. $1{ }^{119}$ Sn CPMG MAS NMR acquired in direct excitation for 2, 5 and 10 Sn-Beta catalysts
32]. Together, these observations indicate that increasing the Sn loading increases the heterogeneity of Sn within the zeolite, and also influences the precise nature of the isomorphously substituted Sn atoms.

This observation of increasing heterogeneity is in line with a previous study, in which we observed that the progressive incorporation of Sn into the Beta framework above levels of $5 \mathrm{wt} \%$ leads to the formation of extra-framework species [23]. In addition to lowering the intrinsic activity of the material during batch operation (turnover frequency (TOF), see Eq. 1 in Sect. 4.4) such species can also partially block access to the micropores of the material [23], likely accounting for the slight decrease in porosity exhibited by 10Sn-Beta (Table S1). However, nothing is known yet about how this increasing heterogeneity of active sites influences continuous operation of the catalyst, in terms of activity and stability. Accordingly, the four catalysts were tested in continuous flow for the glucose isomerisation reaction, with pure $\mathrm{MeOH}$ used as solvent. Being aware that mixtures of $\mathrm{MeOH} /$ water greatly increase the stability of the process by several order of magnitude [22], the intentional choice of using $\mathrm{MeOH}$ as solvent in this work was done in order to have faster rates of deactivation i.e. to allow a systematic study to be performed in a relatively short period of time. Furthermore, utilising pure $\mathrm{MeOH}$ allows identification of which materials are intrinsically more stable to deactivation through the mechanisms we recently identified for Sn-Beta catalysis [21].

Figure 2 presents the relative performance (Eq. 2 in Sect. 4.4) of various Sn-Beta catalysts, containing between

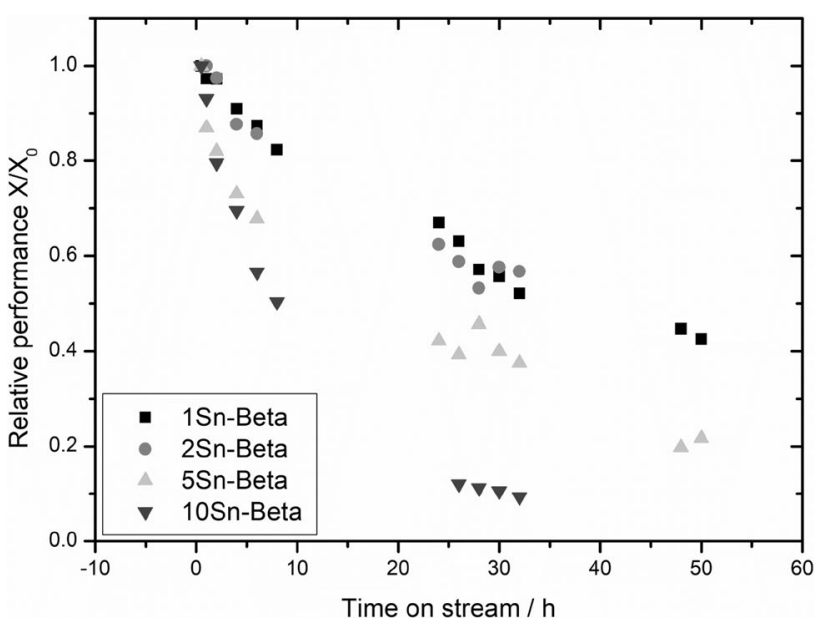

Fig. 2 Relative performance of various Sn-Beta catalysts with different metal loadings for glucose isomerisation as a function of time on stream. Reaction conditions: $1 \mathrm{wt} \%$ of glucose in pure $\mathrm{MeOH}$ at $110{ }^{\circ} \mathrm{C}$, with a backpressure of 10 bar. Catalyst particles of $63-75 \mu \mathrm{m}$ were employed after pressing and sieving. The contact times of the reactions were adjusted in order to start from an initial conversion between 30 and $35 \%$, see Table S2 (entry 1-4) for further details 
1 and $10 \mathrm{wt} \% \mathrm{Sn}$, for glucose isomerisation in $\mathrm{MeOH}$ at $110{ }^{\circ} \mathrm{C}$ as a function of time on stream. We note that the contact time (Eq. 3) of each reaction was adjusted in order that every reaction started from a similar level of conversion (Eq. 4) (ranging between 30 and 35\%), allowing accurate comparison of the stability of the catalysts at similar points of the reaction coordinate [18]. We further note that in all of these reactions, the fructose selectivity (Eq. 5) of the system overlaps at all levels of conversion, implying that the Sn loading of the catalyst does not drastically alter the selectivity of the reaction (Fig. S2). As a preliminary analysis, it can be seen that all the catalysts lose at least $50 \%$ of their initial activity within $48 \mathrm{~h}$ on stream. However, 10- and 5SnBeta demonstrate a lower level of stability, losing $c a .90$ and $60 \%$ of their initial activity, respectively after only $30 \mathrm{~h}$ of operation. In contrast, 1- and 2Sn-Beta appear to have very similar stability during the reaction, showing a loss of approximately $40 \%$ of initial activity over the same $30 \mathrm{~h}$ period. When talking about stability, however, it is often more appropriate to compare the performance of different catalysts against substrate turnover number (indicative of the quantity of substrate that has passed over the catalytic bed). In fact, it is often more important to evaluate the catalyst stability as a function of the number of reactant molecules that have been processed rather than the time on stream, particularly if disparate levels of activity are observed between catalytic materials [15]. Therefore, the relative performances of the catalysts were also compared as function of substrate turnovers (Eq. 6 in Sect. 4.4) in Fig. 3. This analysis shows how much greater the differences of stability are. In fact,

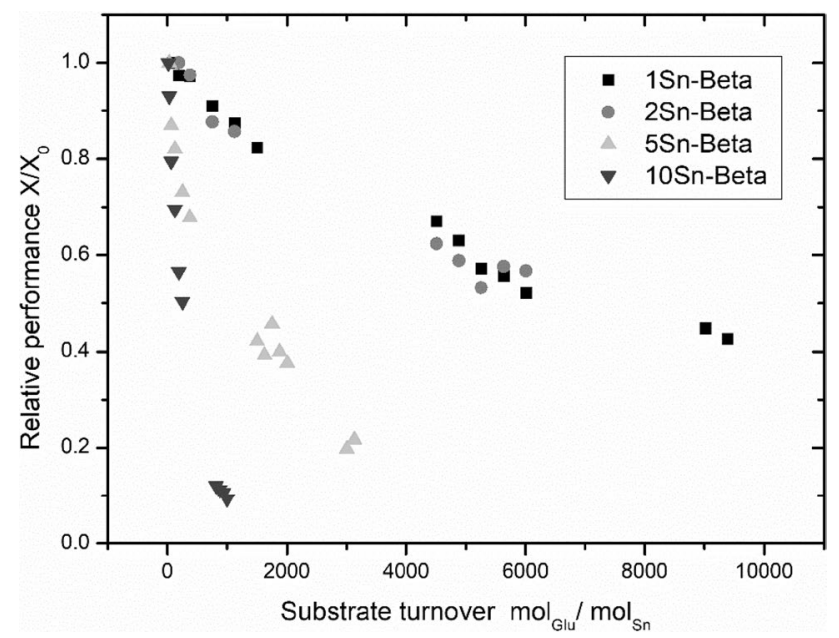

Fig. 3 Relative performance as function of substrate turnover for glucose isomerisation reaction performed with Sn-Beta at different metal loadings. Reaction conditions: $1 \mathrm{wt} \%$ of glucose in pure $\mathrm{MeOH}$ at $110{ }^{\circ} \mathrm{C}$, with a backpressure of 10 bar. Catalyst particles of $63-75 \mu \mathrm{m}$ were employed after pressing and sieving. The contact times of the reactions were adjusted in order to start from an initial conversion between 30 and $35 \%$, see Table S2 for further details after only 1000 substrate turnover, 10Sn-Beta has lost approximately $90 \%$ of its activity, whilst 5 Sn-Beta has lost only $50 \%$ of its initial activity. On the other hand, 1- and 2 Sn-Beta have lost just $10 \%$ of their initial activity at the same number of substrate turnovers, showing remarkably improved stability.

To compare the performance of the series of catalyst in a more quantitative way, the deactivation rate $\left(k_{\mathrm{d}}\right)$ of each catalyst was calculated using the approach described by Levenspiel (Eq. 7) [33]. Additionally, the intrinsic activity of each catalyst was also calculated according to its initial TOF (Eq. 1). As can be seen in Table 1, the calculated deactivation rate showed that samples containing lower amounts of metal were substantially more stable, with deactivation rates of 0.020 and $0.022 \mathrm{~h}^{-1}$ observed for $1 \mathrm{Sn}$-Beta and $2 \mathrm{Sn}$ Beta, respectively. Slightly faster deactivation was observed for $5 \mathrm{Sn}$-Beta $\left(0.033 \mathrm{~h}^{-1}\right)$, and an even larger value of $k_{\mathrm{d}}$ observed for 10Sn-Beta $\left(0.08 \mathrm{~h}^{-1}\right)$. Analysis of the TOF of each sample also showed that at higher loadings of Sn, the intrinsic activity decreased substantially, in line with what we have previously identified during batch operation [26]. However, it should be stressed that the calculation of TOF in continuous flow can be affected by the deactivation, i.e. some contribution of deactivation may already have occurred by the time the first sample was taken. Thus, it can be expected that the precise values of TOF are underestimated, and that the extent of this is different for each sample depending on the deactivation rate of the catalyst.

Previously, we reported that the formation of extra-framework SnOx species was the cause of the decrease in the initial TOF of Sn-Beta catalysts at elevated loadings, and that this process became relevant for loadings higher than 5 wt $\%$. However, in our previous studies, we only investigated the performance of samples with $>2 \mathrm{wt} \% \mathrm{Sn}$. Although the decreased TOF of 10Sn-Beta in this study is in line with our previous work [23], it is notable that the TOF also decreases slightly between 1 - and 2 Sn-Beta. As the ${ }^{119}$ Sn CPMG MAS NMR spectra show that extra-framework $\mathrm{SnOx}$ formation is not a major factor at loadings lower than $5 \mathrm{wt} \%$ (Fig. 1),

Table $1 k_{\mathrm{d}}$ and TOF for Sn-Beta samples containing different Sn loadings $2 \mathrm{Sn}$-Beta, $5 \mathrm{Sn}$-Beta and 10Sn-Beta. Experimental error data is shown in Fig. S3

\begin{tabular}{lll}
\hline Catalyst & $\begin{array}{l}\text { Deactivation constant, } k_{\mathrm{d}} \\
\left(\mathrm{h}^{-1}\right)\end{array}$ & $\begin{array}{l}\text { Turnover } \\
\text { frequency, TOF } \\
\left(\mathrm{h}^{-1}\right)^{\mathrm{a}}\end{array}$ \\
\hline 1Sn-Beta & 0.020 & 70 \\
2Sn-Beta & 0.022 & 55 \\
5Sn-Beta & 0.033 & 27 \\
10Sn-Beta & 0.080 & 10 \\
\hline
\end{tabular}

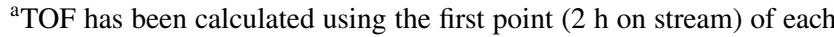
reaction according to Eq. 1 
some other factors must govern the higher intrinsic activity of Sn-Beta at the very lowest loadings. At this stage, we can hypothesise that below $2 \mathrm{wt} \%$ of metal, Sn may generally occupy more favourable positions in the framework i.e. a different $\mathrm{T}$ sites, and that this site is more active resulting in slightly higher TOF values for this material. In a similar manner, the large decrease in TOF of $10 \mathrm{Sn}$-Beta, relative to 5 Sn-Beta, may also be related to the different distribution of active sites in this sample, in addition to the higher quantities of extra-framework SnOx observed in this material (Fig. 1).

This data provides evidence that the metal loading of SnBeta affects not just its intrinsic activity, but also its stability. In particular, when the relative performance of the catalyst is compared as a function of substrate turnover, it appears clear that higher loading catalysts are more prone to deactivate, in addition to being lower in intrinsic activity. This demonstrates that optimal performance, in terms of activity and stability, is attained at the lowest loadings (Fig. 4). As we recently demonstrated that loss of crystallinity and pore fouling are not important factors with respect to deactivation of Sn-Beta for glucose isomerisation in $\mathrm{MeOH}[18,19,21]$, different possible causes of deactivation must explain the lower stability observed at higher loadings of Sn.

One of the main differences between 10Sn-Beta and the samples of lower loading is the increased quantity of extraframework SnOx present, as evidenced by the increased signal at $-600 \mathrm{ppm}$ in the ${ }^{119} \mathrm{Sn}$ CPMG MAS NMR spectrum (Fig. 1). Although our previous studies have indicated that such extra-framework $\mathrm{SnOx}$ species are spectators during catalysis i.e. they do not contribute to catalytic performance

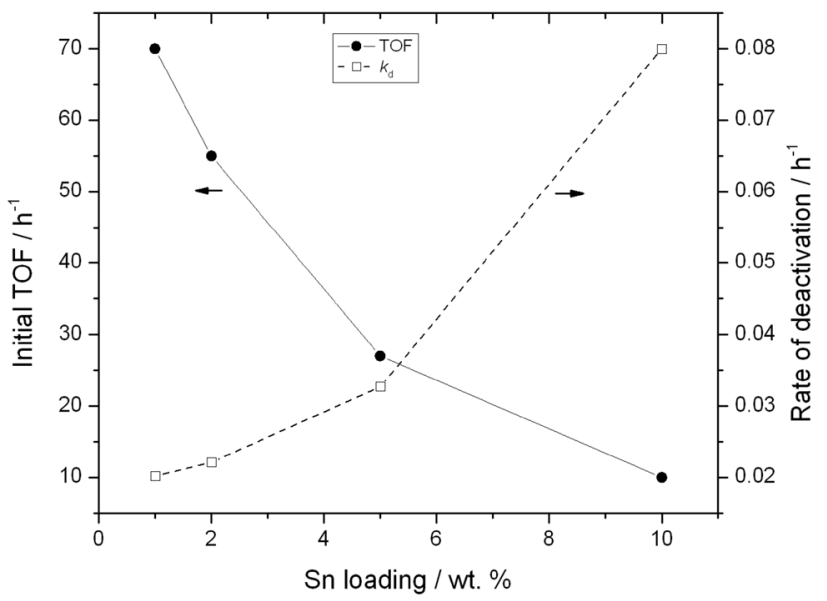

Fig. 4 Impact of Sn loading of Sn-Beta on the initial activity of the catalyst (TOF, left $\mathrm{Y}$ axis) and its rate of deactivation $\left(k_{\mathrm{d}}\right.$, right $\mathrm{Y}$ axis) during glucose isomerisation. Reaction conditions: $1 \mathrm{wt} \%$ of glucose in pure $\mathrm{MeOH}$ at $110{ }^{\circ} \mathrm{C}$, with a backpressure of 10 bar. Catalyst particles of 63-75 $\mu \mathrm{m}$ were employed after pressing and sieving. The contact times of the reactions were adjusted in order to start from an initial conversion between 30 and 35\%, see Table S2 for further details of the material for glucose isomerisation, no knowledge about their potential impact on the lifetime of the catalyst has been described in the literature. In fact, the co-presence of extra-framework $\mathrm{SnOx}$ could still contribute to deactivation of the catalyst, even if such species are inactive for glucose isomerisation, either by participating in a negative side reaction, or by altering the overall physical properties of the material. Thus, to investigate the possible impact of extraframework SnOx species on the lifetime of the material, a continuous flow reaction employing a physical mixture of 2Sn-Beta and $\mathrm{SnO}_{2}$ (at a Sn loading corresponding to $2 \mathrm{wt} \%$, thus a total of $4 \mathrm{wt} \% \mathrm{Sn}$ ) was run under identical reaction conditions to an experiment performed with 2Sn-Beta alone (Fig. 5). As can be seen, the performance of both systems is equal throughout the reaction period. Although it should be stressed that such a physical mixture containing bulk $\mathrm{SnO}_{2}$ may not be fully representative of the SnOx-type clusters found as a secondary species in the SSI-prepared materials, this strongly indicates that the co-presence of SnOx itself in 10Sn-Beta does not negatively influence the stability of the catalyst.

Having ruled out that bulk $\mathrm{SnO}_{2}$ actively participates in deactivation of the catalyst, we explored the possibility that the restructuring of $\mathrm{Sn}$ into additional inactive $\mathrm{SnO}_{\mathrm{x}}$ species during continuous operation could be facilitated when the percentage of $\mathrm{Sn}$ is higher in the material, i.e. if the smaller distance between $\mathrm{Sn}$ atoms in 10Sn-Beta facilitates their agglomeration, and hence loss of activity. To investigate this, ${ }^{119}$ Sn CPMG MAS NMR spectra of 10Sn-Beta and 2SnBeta were acquired before and after continuous operation (ESI Fig. S4). The spectra of both catalysts after continuous

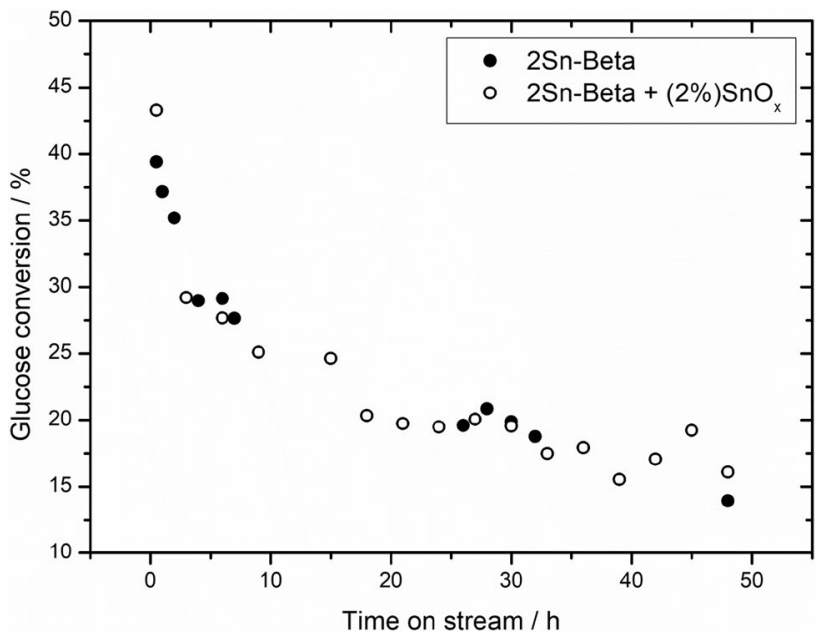

Fig. 5 Conversion as function of time on stream of $2 \mathrm{Sn}$-Beta alone, and a physical mixture of $2 \mathrm{Sn}-\mathrm{Beta}$ and $2 \mathrm{SnO}_{\mathrm{x}}$. Reaction conditions: $1 \mathrm{wt} \%$ of glucose in pure $\mathrm{MeOH}$ at $110{ }^{\circ} \mathrm{C}$, with a backpressure of 10 bar. Catalyst particles of $63-75 \mu \mathrm{m}$ were employed after pressing and sieving. Both reactions started from an initial conversion of $30-35 \%$ 
operation present a growth of the signal at $-600 \mathrm{ppm}$, indicative of $\mathrm{SnO}_{\mathrm{x}}$ species. This indicates some restructuring of framework $\mathrm{Sn}$ into $\mathrm{SnO}_{\mathrm{x}}$ occurs for both high and low loading samples. Although it should be stressed that under CPMG conditions the experimental parameters overestimate the relative contribution of the $-600 \mathrm{ppm}$ signal to that of the $-700 \mathrm{ppm}$ signals, hence prohibiting accurate quantification [21], it is apparent that the degree of increase in the relative intensity of the $-600 \mathrm{ppm}$ signal is comparable for both samples. This indicates that the extent of restructuring is comparable for both samples. However, as the relative activity of the two catalysts measured after the same amount of time on stream is very different, this indicates that the restructuring of $\mathrm{Sn}$ into $\mathrm{SnOx}$ is not the main cause of deactivation, in line with previous observations [21], nor is it the reason for the increasing rate of deactivation at higher loadings of $\mathrm{Sn}$.

Previously, we identified that deactivation of Sn-Beta during continuous glucose isomerisation is caused by strong interaction of the catalyst with $\mathrm{MeOH}$, which results in the loss of $\mathrm{Sn}-\mathrm{OH}$ species widely accepted to be the active sites of Sn-Beta. To study the interaction between solvent and catalyst in more depth, and hence determine whether higher loaded materials possess different intrinsic resistance to $\mathrm{MeOH}$, TPD-MS measurements were performed. To do so, the same mass of 1 and 10Sn-Beta were first stirred at reaction temperature $\left(110^{\circ} \mathrm{C}\right)$ in a pressurised tube containing pure $\mathrm{MeOH}$, were subsequently removed from the tube and dried at room temperature, and analysed by TPDMS, in order to have an indication of the amount of $\mathrm{MeOH}$ retained within the catalysts as the Sn loading increases (Fig. 6). From this analysis, it can be seen that the total amount of $\mathrm{MeOH}(\mathrm{m} / \mathrm{z}=32)$ desorbed from 10Sn-Beta is approximately 2.5 times greater than that of $1 \mathrm{Sn}$-Beta. For both samples, the main desorption occurs at $220^{\circ} \mathrm{C}$, which

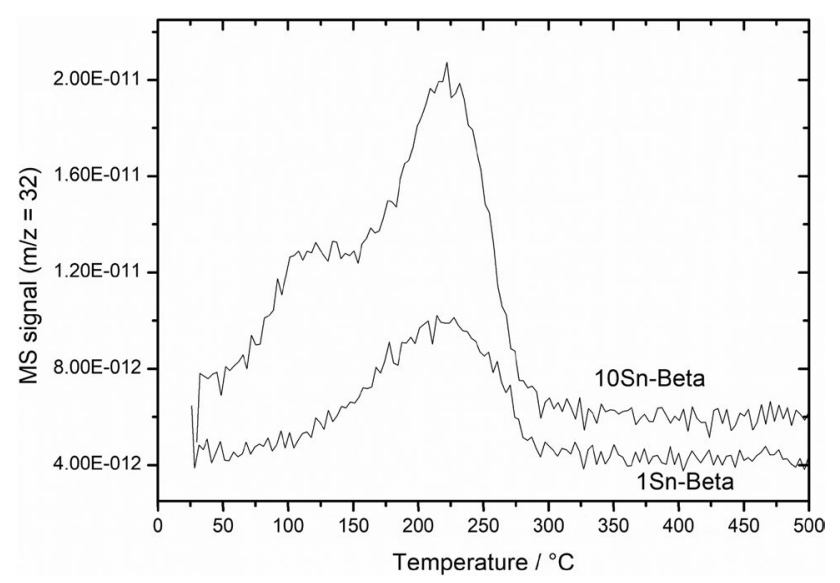

Fig. 6 TPD-MS of 1 and 10Sn-Beta after $\mathrm{MeOH}$ adsorption at $110{ }^{\circ} \mathrm{C}$. The MS-signal displayed is $\mathrm{m} / \mathrm{z}=32$, corresponding to $\mathrm{MeOH}$ can be accredited to $\mathrm{MeOH}$ strongly retained in the zeolite structure. However, 10Sn-Beta also exhibits a second desorption temperature at $110{ }^{\circ} \mathrm{C}$, probably indicative of additional $\mathrm{MeOH}$ weakly bonded to the material, or bonded to a less strong Sn site. As the mass of the catalysts and the conditions of the adsorption were identical, but the Sn loading of 10Sn-Beta is 10 times that of $1 \mathrm{Sn}-\mathrm{Beta}$, it could be expected that more $\mathrm{MeOH}$ would desorb from 10Sn-Beta. However, given the sevenfold decrease in TOF exhibited by 10Sn-Beta, relative to 1 Sn-Beta, per identical mass charge of catalyst (as employed in the kinetic studies) only approximately $40 \%$ more active sites are present per gram of catalyst (Table 1). Thus, the 2.5-fold increase in $\mathrm{MeOH}$ retained per gram of catalyst indicates that more $\mathrm{MeOH}$ is retained per active site for 10Sn-Beta. Having already shown [21] that interaction of $\mathrm{MeOH}$ with the catalyst is the main cause of deactivation, it can by hypothesised that the greater susceptibility of $10 \mathrm{Sn}$-Beta to uptake $\mathrm{MeOH}$ results in its increased rates of deactivation. The greater uptake of $\mathrm{MeOH}$ for this sample may be related to a general increase in organophilic character of the material following the addition of greater amounts of Sn, and/or the different active sites formed in the material at higher loadings (Vide Supra, Fig. 1), which may be less resistant to interaction with $\mathrm{MeOH}$ than those present in 1 Sn-Beta.

\subsection{Comparison Between Post-synthetic and Hydrothermal Sn-Beta}

It is generally recognised that Sn-Beta materials prepared by classical hydrothermal synthesis possess different intrinsic characteristics to those prepared by emerging post-synthetic methods such as SSI. For example, hydrothermally synthesised materials are reportedly more hydrophobic than postsynthetically prepared ones [34-37]. In several reports, the intrinsic activity of the hydrothermal synthesised catalyst also differs to that of its post-synthetic counterpart. These differences are generally attributed to a more efficient incorporation of the Sn into the structure when hydrothermal synthesis is employed, and the more hydrophobic nature of the fluoride-synthesised material [27-30]. However, no clear information about differences of stability between the two classes of Sn-Beta catalysts is known, as extended time on stream testing of otherwise analogous materials has not performed for glucose isomerisation. In order to study these important parameters, a 1Sn-Beta sample synthesised by classical fluoride synthesis (named 1Sn-Beta (HDT)) was tested in the continuous flow system at similar operational conditions to $1 \mathrm{Sn}$-Beta, henceforth re-named as $1 \mathrm{Sn}$-Beta (PS). Due to its superior activity (Vide Infra), the contact time of the reaction with $1 \mathrm{Sn}$-Beta (HDT) was adjusted that both catalysts start from an initial conversion of $32-40 \%$. 
Figure 7 shows the relative performance of 1Sn-Beta (HDT) and $1 \mathrm{Sn}$-Beta (PS) as a function of time of stream.

It can be immediately seen from the initial TOF values of both samples that $1 \mathrm{Sn}$-Beta (HDT) is approximately 2.5 times higher in activity than the post-synthetic material. However, an even greater difference arises when the stability of both the materials is examined. In fact, the $k_{\mathrm{d}}$ values calculated for 1Sn-Beta (HDT) and 1Sn-Beta (PS) are 0.003 and $0.020 \mathrm{~h}^{-1}$, respectively. Hence, an almost sevenfold increase in stability is observed due to the differences in the method of material preparation. A more meaningful comparison of the two systems can again be made by comparing the stability of the catalyst as a function of substrate turnover (Fig. 8). In this case the difference is even more remarkable; After 10,000 substrate turnovers, the post-synthetic material has lost $60 \%$ of its initial activity, while the hydrothermal material has retained almost its entire initial activity. Analysis on the product distribution did not reveal a major difference between the two samples (Table S2). However, it can be noticed that on average, the fructose selectivity for the hydrothermal material is slightly lower when compared at the same level of conversion to that of the post-synthetic material (Fig. 9). In fact, at glucose conversion levels of $30-40 \%$ of glucose conversion, the values of fructose selectivity lay around $35 \%$ for the hydrothermal catalyst, and $45 \%$ in the case of the post-synthetic material. Given its much higher levels of activity and resistance to deactivation, it is clear that hydrothermal synthesis is a more suitable method of Sn-Beta preparation in the context of continuous operation.

Clearly, a remarkable effect on activity and stability is observed when Sn-Beta samples of similar loading (1 wt\%)

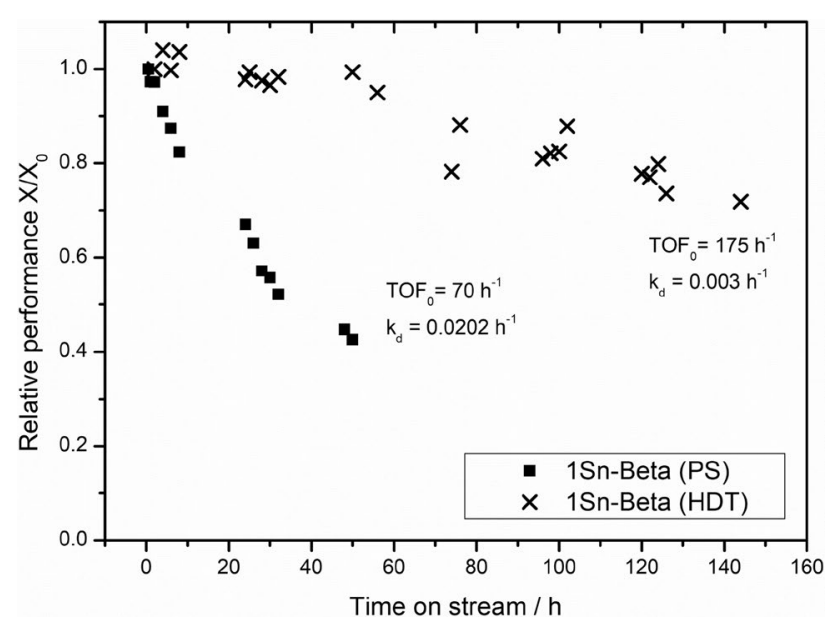

Fig. 7 Relative performance of 1Sn-Beta (PS) and 1Sn-Beta (HDT) for glucose isomerisation as a function of time on stream. Reactions were performed with a solution of $1 \mathrm{wt} \%$ glucose in $\mathrm{MeOH}$, at $110{ }^{\circ} \mathrm{C}$ using $100 \mathrm{mg}$ of catalyst and flow rate of $0.6 \mathrm{~mL} \mathrm{~min}^{-1}$ for 1 Sn-Beta (PS) and $1.4 \mathrm{~mL} \mathrm{~min}^{-1}$ for $1 \mathrm{Sn}-$ Beta (HDT)

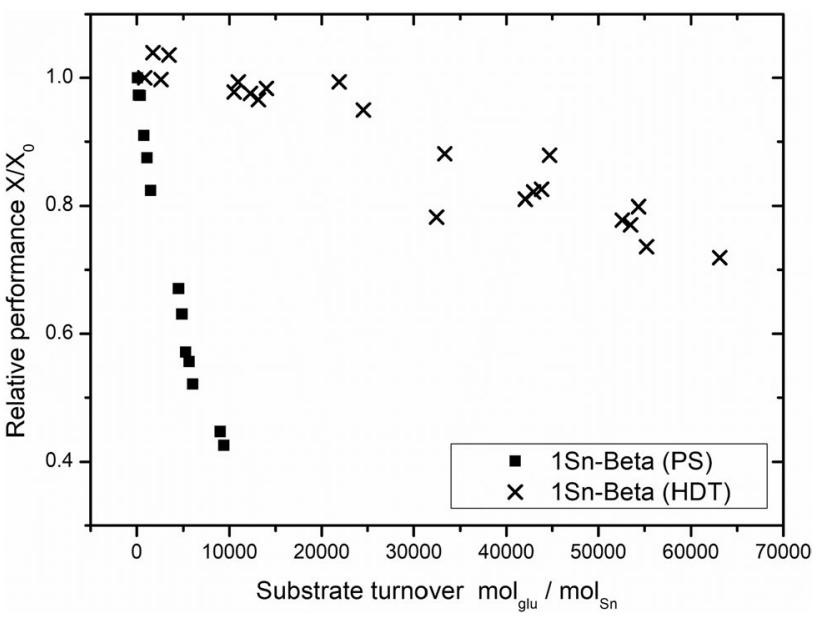

Fig. 8 Relative performances of 1Sn-Beta (PS) and 1Sn-Beta (HDT) for glucose isomerisation as a function of substrate turnovers. Reactions performed with a solution of $1 \mathrm{wt} \%$ glucose in $\mathrm{MeOH}$ at $110^{\circ} \mathrm{C}$ with $100 \mathrm{mg}$ of catalyst and flow rates of $0.6 \mathrm{~mL} \mathrm{~min}{ }^{-1}$ [1Sn-Beta (PS)] and $1.4 \mathrm{~mL} \mathrm{~min}^{-1}$ [1 Sn-Beta (HDT)], see Table S2

are prepared by two different methods. In fact, the hydrothermally synthesised material exhibits a sevenfold increase in stability compared to the post-synthetic counterpart, and a 2.5-time increase in TOF. Such remarkable difference in stability suggests that a profound difference, either in the textural and physical properties of the samples, and/or in the nature of its active sites, exists. The textural properties of the material, such as crystallinity and pore volume, were first characterised, in order to understand if there were evident differences between the two materials. XRD analysis of the two materials show a difference in intensity between

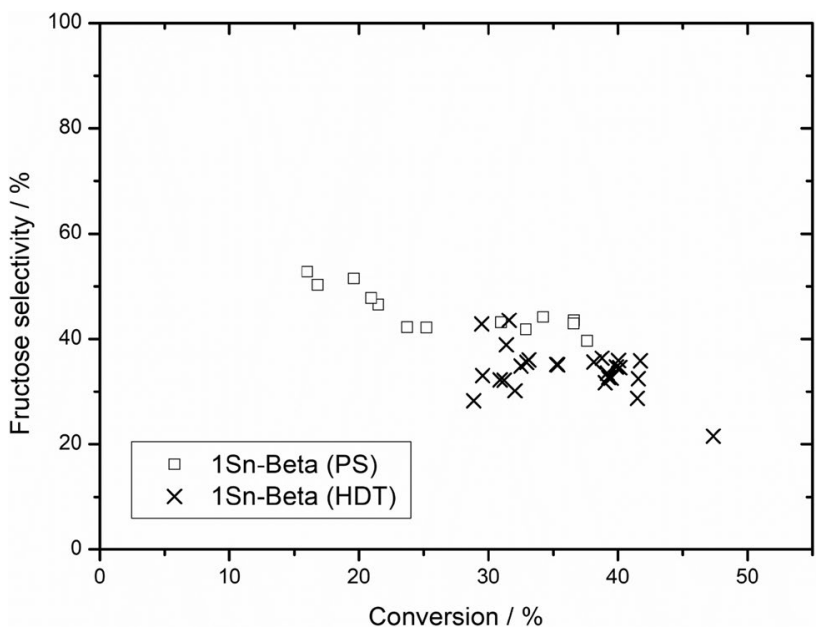

Fig. 9 Fructose selectivity as a function of glucose conversion for 1Sn-Beta (PS) and 1Sn-Beta (HDT). Reactions performed with a solution of $1 \mathrm{wt} \%$ glucose in $\mathrm{MeOH}$ at $110{ }^{\circ} \mathrm{C}$ with $100 \mathrm{mg}$ of catalyst and flow rates of $0.6 \mathrm{~mL} \mathrm{~min}{ }^{-1}$ (1Sn-Beta (PS)) and $1.4 \mathrm{~mL}$ $\mathrm{min}^{-1}(1 \mathrm{Sn}-$ Beta (HDT)), see Table S2 
the diffraction patterns of the two materials, with 1 SnBeta (HDT) showing higher levels of intensity than its postsynthetic counterpart (Fig. 10). However, complementary analysis of the morphology of the catalysts revealed the increase in intensity for $1 \mathrm{Sn}$-Beta (HDT) likely arises from its larger crystallite sizes (Fig. 11). Specifically, 1Sn-Beta (HDT) exhibits particle sizes of 10-15 $\mu \mathrm{m}$, whereas particle sizes between 0.5 and $2 \mu \mathrm{m}$ are found for $1 \mathrm{Sn}$-Beta (PS). Moreover, in previous studies we have ruled out that loss of crystallinity was the cause of deactivation of post-synthetic materials. As such, these differences likely do not account for the lower stability 1 Sn-Beta (PS).

Porosimetry analysis on the two materials was also performed in order to see how the specific surface area and pore volume changes according to the different synthetic methodology (Table 2). As can be seen, the two samples demonstrate different levels of microporosity and surface areas, with 1 Sn-Beta (HDT) exhibiting approximately $30 \%$ lower surface area and micropore volume than 1 Sn-Beta (PS). In light of the lower surface area and porosity exhibited by $1 \mathrm{Sn}-$ Beta (HDT), and the higher intrinsic activity and stability displayed by this material, it can be hypothesised that the factors governing the catalytic properties and the stability of the material are not strongly related to the textural properties. This is in further agreement to our previous studies, where we demonstrated that pore fouling i.e. blocking of the micropores with carbonaceous residue, is not a major contributing factor to deactivation in this system [21]. In summary, it is clear that whilst XRD data and porosimetry data show there are some intrinsic textural differences present between the two materials, satisfactory and conclusive structure-activity-stability relationships cannot be achieved with these two techniques alone. Hence, studies of the active sites of both samples are required.

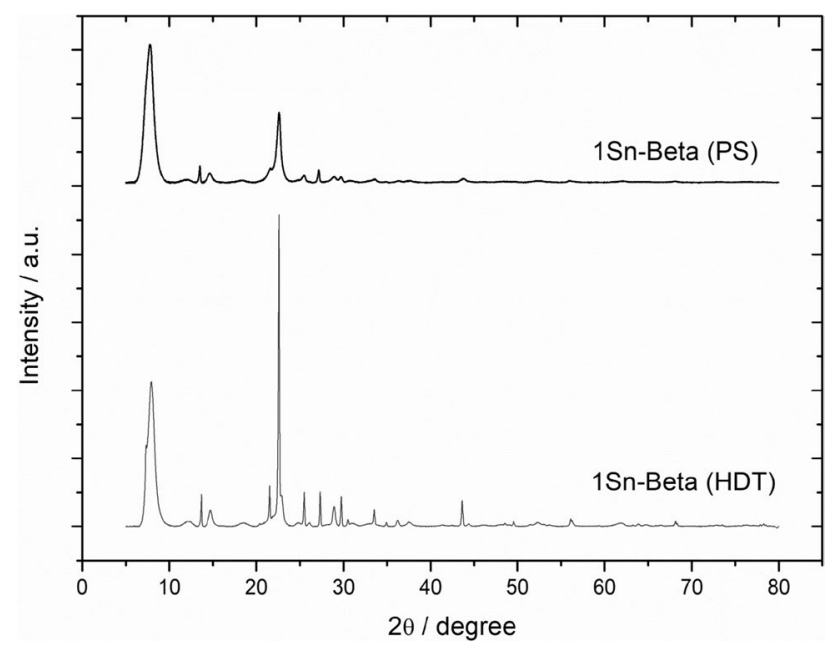

Fig. 10 XRD patterns of 1Sn-Beta (PS) and 1Sn-Beta (HDT)
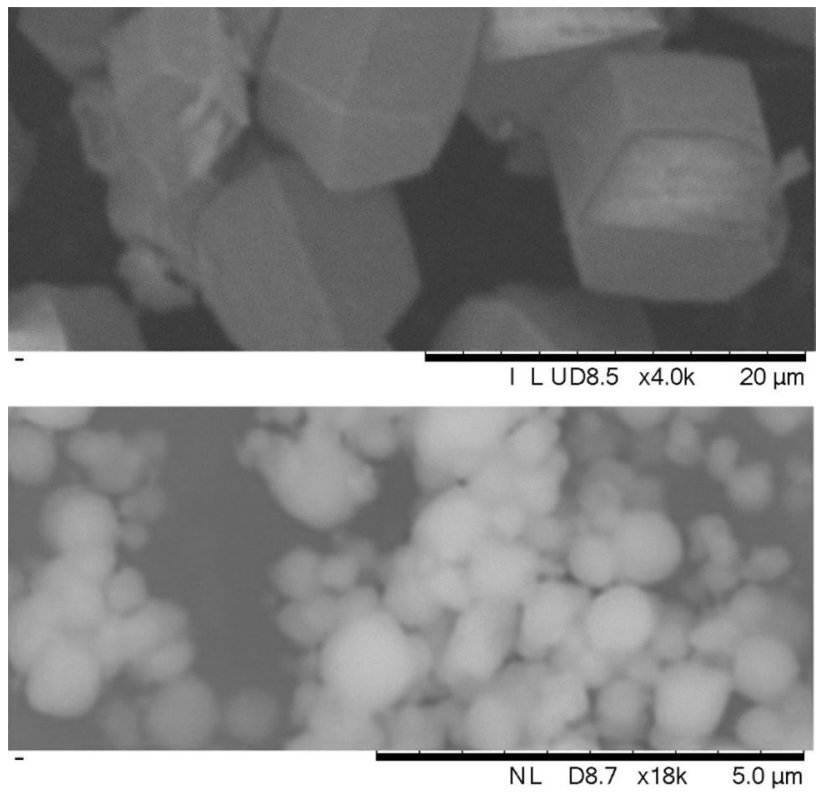

Fig. 11 SEM micrographs of 1Sn-Beta (HDT) (top) and1Sn-Beta (PS) (bottom); magnification for each micrograph is specified beneath each box

As described above, we have demonstrated that the primary mechanism of deactivation during glucose conversion with Sn-Beta arises from the strong interaction between the catalyst and the $\mathrm{MeOH}$ solvent. Indeed, operando UV-Vis analysis on catalysts performing glucose isomerisation in pure $\mathrm{MeOH}$ revealed that a strong negative absorption occurs at around $220 \mathrm{~nm}$ upon interaction of $\mathrm{Sn}$ with $\mathrm{MeOH}$, and that the appearance of this absorption correlated to deactivation of the catalyst [21]. Thus, to further investigate the improved stability of $1 \mathrm{Sn}$-Beta (HDT) relative to $1 \mathrm{Sn}$-Beta (PS), the two samples were re-examined for glucose isomerisation, this time with operando UV-Vis being performed. We note that the kinetic data obtained with the operando reactor matches the data obtained in the conventional flow reactor (Fig. S5). The resulting spectra of the first $20 \mathrm{~h}$ on stream under the UV probe are shown in Fig. 12. As can be seen, over the course of $20 \mathrm{~h}$ on stream, 1Sn-Beta (PS) experiences a steady decrease in absorbance at $220 \mathrm{~nm}$. Over this period of time, the catalyst also loses approximately $30 \%$

Table 2 Porosimetry data for 1Sn-Beta (PS) and 1Sn-Beta (HDT)

\begin{tabular}{lll}
\hline Catalyst & $\begin{array}{l}\text { Specific surface are }\left(\mathrm{m}^{2}\right. \\
\left.\mathrm{g}^{-1}\right)^{\mathrm{a}}\end{array}$ & $\begin{array}{l}\text { Micropore } \\
\text { volume }\left(\mathrm{cm}^{3}\right. \\
\left.\mathrm{g}^{-1}\right)^{\mathrm{a}}\end{array}$ \\
\hline 1Sn-Beta (PS) & 581 & 0.245 \\
1Sn-Beta (HDT) & 391 & 0.168 \\
\hline
\end{tabular}

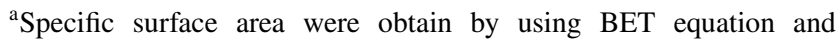
micropore volume were obtained from t-plot method 


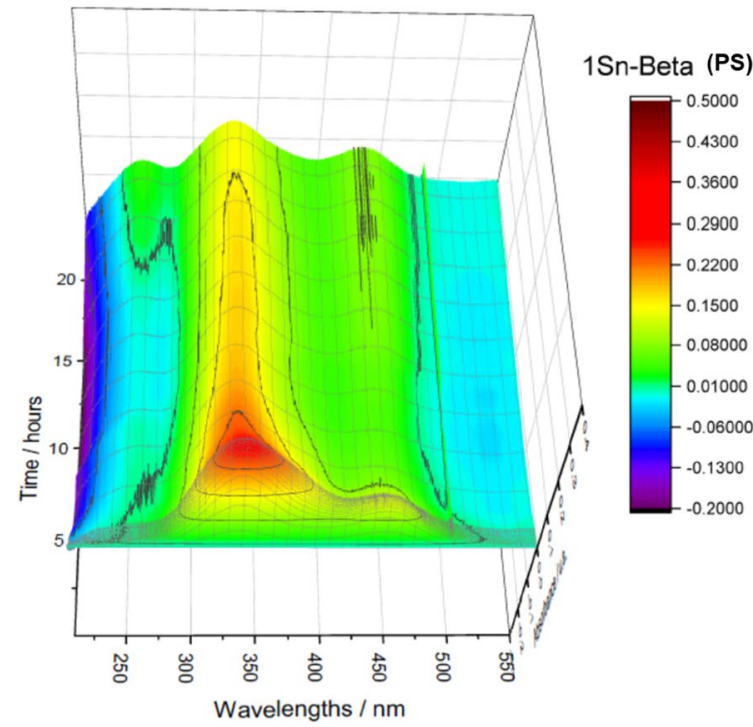

Fig. 12 Operando UV-Vis following the isomerisation of glucose in pure $\mathrm{MeOH}$ for (Left) 1Sn-Beta (PS) and (Right) 1Sn-Beta (HDT). Reactions performed with a solution of $1 \mathrm{wt} \%$ glucose in $\mathrm{MeOH}$

of its catalytic performance. In contrast, the hydrothermal material experiences very little negative absorbance in this region over the same reaction period, clearly demonstrating that interaction between $\mathrm{Sn}$ and $\mathrm{MeOH}$ is greatly reduced for this sample. Importantly, this sample also exhibits no loss in activity over this reaction period. Alongside this, the band at $340 \mathrm{~nm}$, attributed to interaction between $\mathrm{Sn}$ and glucose [21], is much stronger in $1 \mathrm{Sn}-\mathrm{Beta}$ (HDT), whereas for $1 \mathrm{Sn}$ Beta (PS) it decreases in intensity with time.

From the operando UV-Vis measurements, it is clear that the hydrothermally synthesised material better inhibits the Sn sites of the catalyst from interacting strongly with $\mathrm{MeOH}$, somehow mimicking what small quantities of water molecules do in the post-synthetic sample, whilst at the same time helping the interaction of $\mathrm{Sn}$ with glucose. To further study the interaction between catalyst and $\mathrm{MeOH}$, TPD-MS was performed, following treatment of both samples in pure $\mathrm{MeOH}$ at $110^{\circ} \mathrm{C}$ for $1 \mathrm{~h}$ (Fig. 13). From this (Fig. 13) it can be seen that the quantity of $\mathrm{MeOH}$ evolved from the two samples is comparable, as the area of the $\mathrm{MeOH}$ signal is of similar magnitude for both TPD-MS profiles. However, the temperature at which the $\mathrm{MeOH}$ evolved is quite different for the two materials. In particular, in $1 \mathrm{SnBeta}$ (HDT) retained $\mathrm{MeOH}$ is evolved at approximately $150^{\circ} \mathrm{C}$, while $\mathrm{MeOH}$ is desorbed at $220^{\circ} \mathrm{C}$ in $1 \mathrm{Sn}$-Beta (PS). The similar quantity of $\mathrm{MeOH}$ retained in the materials after treatment indicates that $\mathrm{MeOH}$ is likely bonded to $\mathrm{Sn}$, since the percentage of metal in the two catalysts is similar. However, the strength of the MeOH-Sn interaction clearly differs. This indicates that the two synthetic routes result in different Sn species, or Sn species present in a different environment. The higher

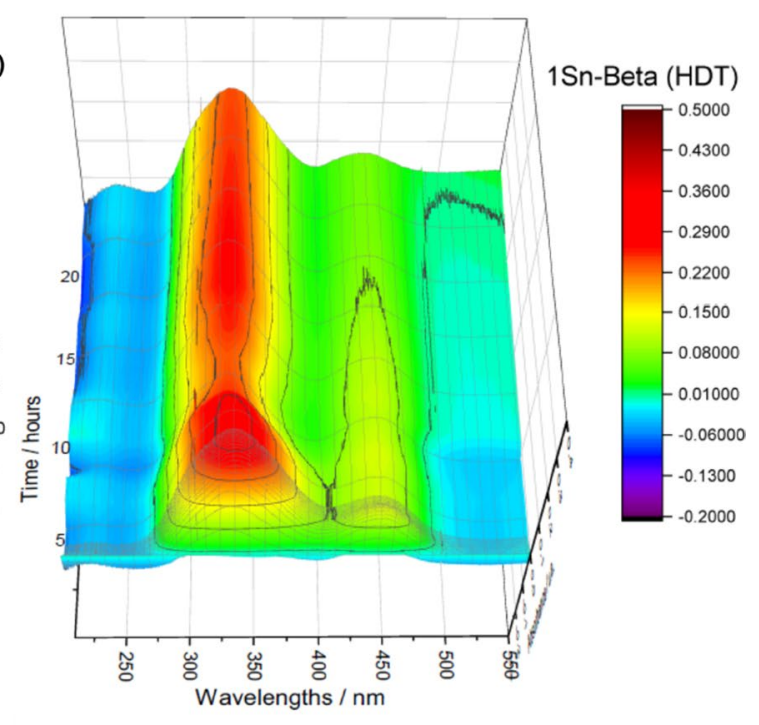

at $110{ }^{\circ} \mathrm{C}$ with $100 \mathrm{mg}$ of catalyst with a flow rate of $0.6 \mathrm{~mL}$ and $1.4 \mathrm{~mL} \mathrm{~min}^{-1}$ for $1 \mathrm{Sn}-\mathrm{Beta}(\mathrm{PS})$ and $1 \mathrm{Sn}-\mathrm{Beta}$ (HDT), respectively

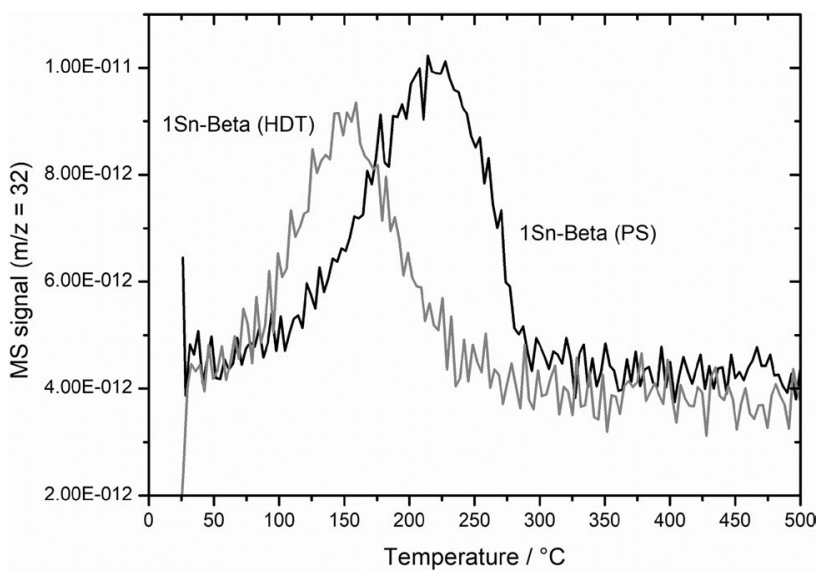

Fig. 13 TPD-MS of 1Sn-Beta (PS) and 1Sn-Beta (HDT) obtained following dosing of the samples in pure $\mathrm{MeOH}$ at $110{ }^{\circ} \mathrm{C}$ for $1 \mathrm{~h}$, and subsequent drying at room temperature

tendency of 1Sn-Beta (PS) to interact with $\mathrm{MeOH}$ is in good agreement to the UV-Vis analysis, and the lower stability of the catalyst under reaction conditions.

To gain further insight of catalyst-solvent interactions, vapour adsorption isotherms with $\mathrm{MeOH}$ and water were performed for $1 \mathrm{Sn}-\mathrm{Beta}$ (HDT) and 1Sn-Beta (PS). As can be seen (Fig. 14, Left), both catalysts adsorb different quantities of $\mathrm{MeOH}$ by different mechanisms. Specifically, whereas $\mathrm{MeOH}$ adsorption over $1 \mathrm{Sn}$-Beta (38) is typical of a Type I isotherm, representative of micropore condensation driven by adsorbate-adsorbent interactions, $\mathrm{MeOH}$ adsorption over $1 \mathrm{Sn}$-Beta (HDT) is more typical of a Type 
Fig. 14 Vapour isotherms of $\mathrm{MeOH}$ (Left) and water (Right) for 1Sn-Beta (PS) and 1Sn-Beta (HDT) at $20^{\circ} \mathrm{C}$

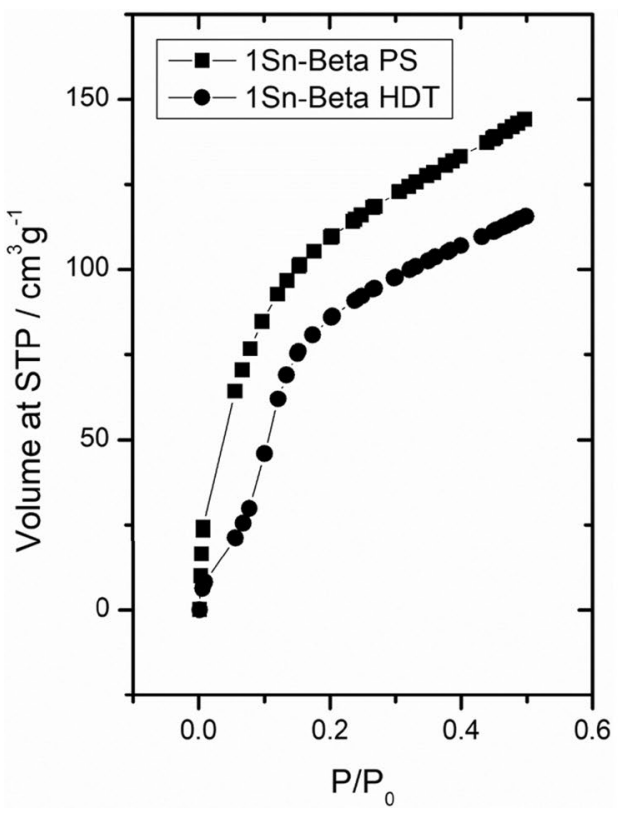

$\mathrm{V}$ isotherm, representative of micropore condensation driven by adsorbate-adsorbate interactions [38]. As such, it is likely that $\mathrm{MeOH}$ tends to adsorb to $1 \mathrm{Sn}$-Beta (PS) directly on the acid sites ( $\mathrm{Sn}$, or $\mathrm{Si}-\mathrm{OH}$ groups close to $\mathrm{Sn}$ ), but $\mathrm{MeOH}$ adsorption by $1 \mathrm{Sn}-\mathrm{Beta}$ (HDT) is achieved by $\mathrm{MeOH}$ molecules interacting with other $\mathrm{MeOH}$ molecules. This observation indicates lower interaction of $\mathrm{MeOH}$ with the Sn sites of 1Sn-Beta (HDT), in excellent agreement to the lower desorption temperature observed for $\mathrm{MeOH}$ for this material compared to $1 \mathrm{Sn}$-Beta (PS). In addition to reflecting different adsorption behaviour, it is notable that different quantities of $\mathrm{MeOH}$ are also adsorbed by both samples in the low pressure regime, with 1 Sn-Beta (PS) adsorbing approximately twice the amount of $\mathrm{MeOH}$ than $1 \mathrm{Sn}-\mathrm{Beta}(\mathrm{HDT})$ at $\mathrm{P} / \mathrm{P}_{0}=0.1$. This observation clearly indicates that $1 \mathrm{Sn}$-Beta (HDT) is substantially more resistant to $\mathrm{MeOH}$ adsorption, even at the same metal loading as $1 \mathrm{Sn}$-Beta (PS). More dramatic again is the difference in the amount of water adsorbed by 1 Sn-Beta (HDT) than 1 Sn-Beta (PS) (Fig. 14, Right). In fact, 1 Sn-Beta (PS) shows a much higher water uptake than the hydrothermal catalyst at comparable pressures, in perfect agreement with previous reports where the more hydrophobic nature of the hydrothermal material has been identified $[27,29]$. Taken together, these results clearly demonstrate that the hydrothermally prepared material represents a more protected environment for the Sn sites of the catalyst from both water and $\mathrm{MeOH}$. Even though differences in solvent uptake between the two materials are clearly observed by TPD-MS and vapour absorption measurements, it cannot yet be deduced if this is due to an overall difference in the zeolite structure itself i.e. different porosity, different number of connectivity defects, presence of silanol groups, amongst others, or whether it relates to a specific type of $\mathrm{Sn}$ species uniquely present in 1 Sn-Beta (HDT).

Thus, to see if the two diverse synthetic routes generate actual differences in the Sn speciation, ${ }^{119} \mathrm{Sn}$ CPMG MAS NMR was performed. From the two spectra shown in Fig. 15, it can be seen immediately that the major resonances in 1Sn-Beta (HDT) and 1Sn-Beta (PS) are slightly shifted, resonating at -690 and $-710 \mathrm{ppm}$, respectively. These signals lie in the spectral region representative of hexa-coordinated framework Sn sites, known to result in catalytic activity [33, 34]. In 1 Sn-Beta (PS) a minor signal is also present at $-600 \mathrm{ppm}$, which indicates the presence of

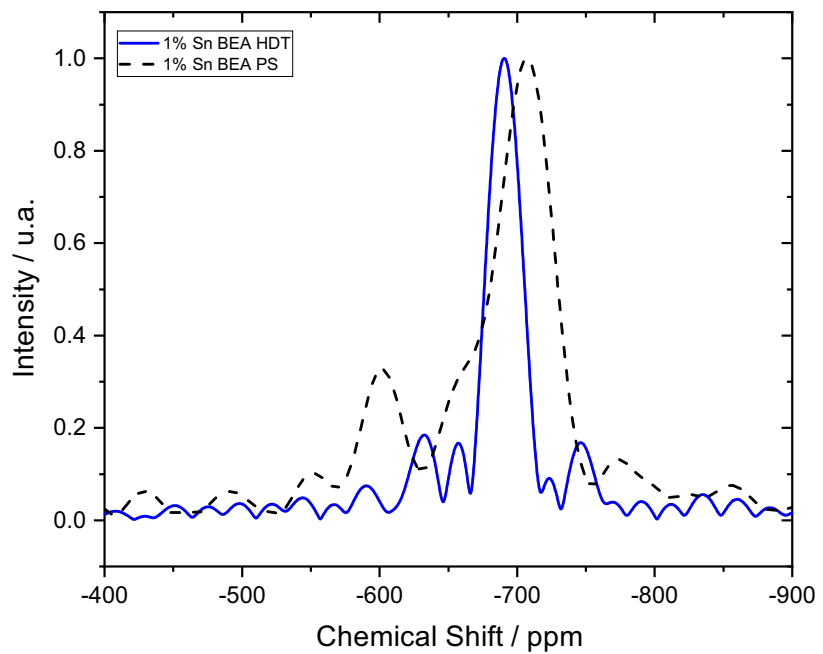

Fig. $15{ }^{119}$ Sn DE CPMG MAS NMR spectra of 1Sn-Beta (PS) (dotted line) and 1Sn-Beta (HDT) (solid line) 
some extra-framework $\mathrm{SnO}_{\mathrm{x}}$ species in this sample. As the level of extra-framework $\mathrm{SnOx}$ is low, and with the chosen recycle delay times it is an overestimate of its real contribution to the population, it will not account for the 2.5 -fold decrease in TOF exhibited by this sample relative to the hydrothermal, although it will evidently contribute somewhat. However, the precise chemical shift of both samples differs substantially, by approximately $20 \mathrm{ppm}$. Despite the fact that exact nature of the active sites of the two materials is unknown, such differences in chemical shift clearly relate to differences in the environment and nature of the active sites of both catalysts. In addition to reflecting changes in intrinsic activity, such changes could also result in different degrees of stability. In fact, changes in chemical shift could arise not only from a different form of the active site e.g. open or closed, but also from a different location in the zeolite structure (T site) [35-37]. Thus, it can be hypothesised that sites located in different crystallographic positions of the framework might possess different stability, being more or less intrinsically stable and/or being more or less exposed to the deactivation processes we have identified. The genesis of this difference likely arises from the different methods of incorporation i.e. direct insertion of Sn into its most favourable T-site during hydrothermal synthesis, versus post-synthetic incorporation of $\mathrm{Sn}$ into the most favourable T-site for incorporation of $\mathrm{Al}$.

\section{Conclusions}

In this work, a systematic study of Sn-Beta catalyst performing continuous glucose isomerisation has been performed, in order to identify how particular properties of the material play a role in determining the stability of catalyst, in addition to its activity and selectivity. First, the effect on the metal loading was explored, employing four post-synthetic SnBeta samples with Sn loadings of 1, 2, 5 and $10 \mathrm{wt} \%$. These studies demonstrate that at low metal loadings, both stability and intrinsic activity are maximised. Kinetic and TPD-MS studies on 1 and 10Sn-Beta, representing low and high Sn containing zeolites, showed that the 10Sn-Beta interacts greater with $\mathrm{MeOH}$. Given the role $\mathrm{MeOH}$ adsorption plays in deactivation, it is hypothesised that the higher amount of $\mathrm{MeOH}$ taken from high loading samples leads to more rapid rates of deactivation by strong adsorption between $\mathrm{Sn}$ and $\mathrm{MeOH}$. Finally, samples prepared by different preparation methods, post-synthetic incorporation and direct hydrothermal synthesis, were compared at the same $1 \mathrm{wt} \%$ loading. This revealed that the hydrothermally synthesised material is both more stable and more active than the postsynthetic material, showing a sevenfold increase in stability and 2.5-fold increase in activity. The better performance of the hydrothermal catalyst is attributed by several techniques, including TPD-MS, vapour adsorption studies and operando $\mathrm{UV}-\mathrm{Vis}$ spectroscopy, to its greater resistance to interaction with the solvent, $\mathrm{MeOH}$. As we have previously demonstrated that interaction between $\mathrm{Sn}$ and $\mathrm{MeOH}$ is the major cause of deactivation in this system, minimising this evidently increases stability of the catalyst. Complementary studies by ${ }^{119} \mathrm{Sn}$ CPMG MAS NMR show that the Sn sites in the two materials possessed distinct chemical shifts, indicating that the active sites on the two catalysts are different, and may be situated in different locations within the zeolite. The improved resistance to deactivation by interaction with $\mathrm{MeOH}$ is therefore tentatively attributed to the presence of different $\mathrm{Sn}$ sites in the catalyst, in addition to the less hydrophilic hydrothermal material, which results in lower levels of interaction between the catalyst and the solvent. Future work will address the nature of Sn active sites present in both of these classes of catalyst, and identify whether post-synthetic methods can be tuned as to prepare truly analogous samples to those obtained by hydrothermal synthesis.

\section{Experimental Details}

\subsection{Catalyst Preparation}

Post-synthetic Sn-Beta samples were prepared by SSI (see reference 24). Commercial Al-Beta (Zeolyst, $\mathrm{NH}_{4}{ }^{+}$-form, $\mathrm{Si}_{2} \mathrm{O} / \mathrm{Al}_{2} \mathrm{O}_{3}=38$ ) was dealuminated by treatment in $\mathrm{HNO}_{3}$ solution (13 $\mathrm{M} \mathrm{HNO}_{3}, 100{ }^{\circ} \mathrm{C}, 20 \mathrm{~mL} \mathrm{~g}^{-1}$ zeolite, $20 \mathrm{~h}$ ). SSI of dealuminated zeolite Beta was performed by grinding the appropriate amount of tin (II) acetate with the necessary amount of dealuminated zeolite for $10 \mathrm{~min}$ in a pestle and mortar. Following this procedure, the samples were heated in a combustion furnace (Carbolite MTF12/38/400) to $550{ }^{\circ} \mathrm{C}$ $\left(10{ }^{\circ} \mathrm{C} \mathrm{min}{ }^{-1}\right.$ ramp rate) first in a flow of $\mathrm{N}_{2}(3 \mathrm{~h})$ and subsequently air $(3 \mathrm{~h})$ for a total of $6 \mathrm{~h}$. Gas flow rates of $60 \mathrm{~mL}$ $\min ^{-1}$ were employed at all times.

Hydrothermal synthesis of Sn-Beta was performed following a procedure described in literature [39]: $30.6 \mathrm{~g}$ of TEOS was added to $33.1 \mathrm{~g}$ of TEAOH under careful stirring, forming a two-phase system. After 60-90 min, one phase was obtained and the desired amount of the tin source, typically $\mathrm{SnCl}_{4} \cdot 5 \mathrm{H}_{2} \mathrm{O}$, dissolved in $2.0 \mathrm{~mL}$ of $\mathrm{H}_{2} \mathrm{O}$ was added dropwise. The solution was then left for several hours under stirring until a viscous gel was formed. The gel was finalised by the addition of $3.1 \mathrm{~g} \mathrm{HF}$ in $1.6 \mathrm{~g}$ of demineralized $\mathrm{H}_{2} \mathrm{O}$ yielding a solid gel with the molar composition; 1.0Si:xSn $: 4 \mathrm{xCl}^{-1}: 0.55 \mathrm{TEA}^{+}: 0.55 \mathrm{~F}^{-1}: 7.5 \mathrm{H}_{2} \mathrm{O}$, where $\mathrm{x}$ ranged from 0.0025 to 0.01 . The obtained gel was transferred in a Teflon lined stainless steel autoclave and kept for 7 days at $140{ }^{\circ} \mathrm{C}$ to crystallise. The obtained crystals were filtered and washed with deionised water. Calcination at $550{ }^{\circ} \mathrm{C}\left(2{ }^{\circ} \mathrm{C} \mathrm{min}-1\right)$ for 
$6 \mathrm{~h}$ under static air was carried out in order to remove the organic template.

\subsection{Kinetic Studies}

Continuous GI reactions were performed in a plug flow, stainless steel, tubular reactor. The reactor was connected to an HPLC pump in order to regulate the reactant flow and allow operation at elevated pressures. The catalyst was pelletised and particle size comprised between 63 and $77 \mu \mathrm{m}$ were selected and placed in between two plugs of quartz wool. The catalyst was densely packed into a $1 / 4$ " stainless steel tube ( $4.1 \mathrm{~mm}$ internal diameter), and a frit of $0.5 \mu \mathrm{m}$ was placed at the reactor exit. The reactor was subsequently immersed in a thermostatted oil bath at the desired reaction temperature. Pressure in the system was controlled by means of a backpressure regulator, typically set at 10 bar, in order to allow operations above the boiling temperature of the solvent. Aliquots of the reaction solutions were taken periodically from a sampling valve placed after the reactor and analysed by an Agilent 1260 Infinity HPLC equipped with a Hi-Plex Ca column and ELS detector and quantified against an external standard (sorbitol) added to the sample prior the injection.

\subsection{Catalyst Characterisation}

XRD spectra were acquire using a PANalytical X'PertPRO $\mathrm{X}$-ray diffractometer. A CuK $\alpha$ radiation source $(40 \mathrm{kV}$ and $30 \mathrm{~mA}$ ) was utilised. Diffraction patterns were recorded between $6-55^{\circ} 2 \theta$ (step size $0.0167^{\circ}$, time/step $=150 \mathrm{~s}$, total time $=1 \mathrm{~h}$ ). TPD-MS measurement were carried out on a home-made system formed by a Bruker Tensor II equipped with a Harrick praying mantis DRIFT cell connected with the MS. The catalyst was placed inside the cell, and the cell then heated from 30 to $600{ }^{\circ} \mathrm{C}$ (ramp rate $10{ }^{\circ} \mathrm{C} / \mathrm{min}$ ) under a constant flow of $\mathrm{N}_{2}$ during all the experiment. The outlet of the DRIFT cell was connected to a Hiden QGA mass spectrometer for the online analysis of the gas phase. The samples were stirred in $\mathrm{MeOH}$ at $110^{\circ} \mathrm{C}$ for $1 \mathrm{~h}$ and let dry at room temperature. Operando UV-Vis measurements were performed with a homemade tubular reactor equipped with fibre optic UV-Vis probe. UV-Vis measurements were performed with a light source (Ocean Optics DH-2000), spectrometer (Maya 2000 Pro, Ocean Optics) and a $600 \mu \mathrm{m} \mathrm{UV}-\mathrm{Vis}$ fibre. The light was directed onto an optically transparent reactor column, located within a heated aluminium block. Specific surface area was determined from nitrogen adsorption using the BET equation, and microporous volume was determined from nitrogen adsorption isotherms using the t-plot method. Porosimetry measurements were performed on a Quantachrome Quadrasorb, and samples were degassed prior to use $\left(300{ }^{\circ} \mathrm{C}, 6 \mathrm{~h}\right.$,
$10^{-6}$ bar). Zeolite imaging has been captured using a Hitachi Tabletop microscope TM3030. Images have been acquired at $5 \mathrm{kV}$ and $15 \mathrm{kV}$ at different magnifications specified in the main text. MAS NMR analysis was performed at Durham University through the National Solid-State NMR service. All the samples were nonenriched and were measured on a Bruker Avance III HD spectrometer at operating frequency of $149 \mathrm{MHz}$ for ${ }^{119} \mathrm{Sn}$. Typically, between 50 and $100 \mathrm{mg}$ of solid sample was packed in a $4 \mathrm{~mm}$ rotor and spun at \pm 12 $000 \mathrm{~Hz}$. Samples were measured by the CPMG method as described in reference 32 . Spectra were acquired in direct excitation with a recycle delay time of $2 \mathrm{~s}$ (Fig. 1) and $1 \mathrm{~s}$ (Fig. 15).

\subsection{Formula and Mathematical Expression}

Turnover frequency : TOF $=\frac{\mathrm{mol}_{g l u(0)}-\mathrm{mol}_{g l u(t)}}{h \times \mathrm{mol}_{S n}}$

Relative performance $=\frac{X_{(t)}}{X_{(0)}}$

Contact time : $\tau=\frac{\text { volume }_{(\text {catalyst })}}{\text { flow rate }}$

Conversion: $X(\%)=\frac{m o l_{g l u(0)}-m o l_{g l u(t)}}{m o l_{g l u(0)}} \times 100$

Selectivity:S $(\%)=\frac{m o l_{f r u(t)}}{m o l_{g l u(0)}-m o l_{g l u(t)}} \times 100$

Substrate turnover: $\rho=\frac{\text { ol }_{\text {glu }} \text { permin } x_{t}}{\text { mol }_{S n}}$

Levenspiel deactivation rate: $\ln \left(\ln \left(\frac{[G l u]_{0}}{[G l u]_{t}}\right)\right)=\ln (k \tau)-k_{d} t$

Yield: $Y(\%)=\frac{\text { mol }_{f r u(t)}}{\operatorname{mol}_{g l u(0)}} \times 100$

Acknowledgements $\mathrm{CH}$ gratefully appreciates the support of The Royal Society, for provision of a University Research Fellowship (UF140207). CH and LB are grateful to Haldor Topsøe A/S for further research funding. $\mathrm{CH}$ and $\mathrm{DP}$ are grateful to The Royal Society for research grant funding (CHGIR1\170092). $\mathrm{RN}$ and $\mathrm{CH}$ appreciate the support of Consejo Nacional de Ciencia y Tecnologia (CONACyT) for PhD studentship funding. Dr. David Apperley (Durham University) is acknowledged for support with MAS NMR measurements. 
Open Access This article is distributed under the terms of the Creative Commons Attribution 4.0 International License (http://creativeco mmons.org/licenses/by/4.0/), which permits unrestricted use, distribution, and reproduction in any medium, provided you give appropriate credit to the original author(s) and the source, provide a link to the Creative Commons license, and indicate if changes were made.

\section{References}

1. Vennestrøm PNR, Osmundsen CM, Christensen CH, Taarning E (2011) Beyond petrochemicals: the renewable chemicals industry. Angew Chem Int Ed 50:10502-10509

2. Delidovich I, Leonhard K, Palkovits R (2014) Cellulose and hemicellulose valorisation: an integrated challenge of catalysis and reaction engineering. Energy Environ Sci 7:2803-2830

3. Tuck CO, Pérez E, Horváth IT, Sheldon RA, Poliakoff M (2012) Valorization of biomass: deriving more value from waste. Science 337:695-700

4. Rosatella AA, Simeonov SP, Frade RFM, Alfonso CAM (2011) 5-Hydroxymethylfurfural (HMF) as a building block platform: biological properties, synthesis and synthetic applications. Green Chem $13: 754$

5. Dusselier M, Van Wouwe P, Dewaele A, Makshina E, Sels BF (2013) Lactic acid as a platform chemical in the biobased economy: the role of chemocatalysis. Energy Environ Sci 6:1415-1442

6. Sølvhøj A, Taarning E, Madsen R (2016) Methyl vinyl glycolate as a diverse platform molecule. Green Chem 18:5448-5455

7. Ennaert T, Van Aelst J, Dijkmans J, De Clercq R, Schutyser W, Dusselier M, Verboekend D, Sels B (2016) Potential and challenges of zeolite chemistry in the catalytic conversion of biomass. Chem Soc Rev 45:584-611

8. Climent MJ, Corma A, Iborra S (2014) Conversion of biomass platform molecules into fuel additives and liquid hydrocarbon fuels. Green Chem 16:516-547

9. Zhang X, Wilson K, Lee AF (2016) Heterogeneously catalyzed hydrothermal processing of C5-C6 sugars. Chem Rev 116:12328-12368

10. Moliner M, Román-Leshkov Y, Davis ME (2010) Tin-containing zeolites are highly active catalysts for the isomerization of glucose in water. Proc Natl Acad Sci 107: 6164-6168

11. Román-Leshkov Y, Moliner M, Labinger JA, Davis ME (2010) Mechanism of glucose isomerization using a solid Lewis acid catalyst in water. Angew Chem Int Ed 49:8954-8957

12. Holm MS, Saravanamurugan S, Taarning E (2010) Conversion of sugars to lactic acid derivatives using heterogeneous zeotype catalysts. Science 328:602-605

13. Tolborg S, Sádaba I, Osmundsen CM, Fristrup P, Holm MS, Taarning E (2015) Tin-containing silicates: alkali salts improve methyl lactate yield from sugars. ChemSusChem 8:613-617

14. Lange JP (2015) Renewable feedstocks: the problem of catalyst deactivation and its mitigation. Angew Chem Int Ed 54:13187-13197

15. Hammond C (2017) Intensification studies of heterogeneous catalysts: probing and overcoming catalyst deactivation during liquid phase operation. Green Chem 19:2711-2728

16. Sádaba I, López Granados M, Riisager A, Taarning E (2015) Deactivation of solid catalysts in liquid media: the case of leaching of active sites in biomass conversion reactions. Green Chem 17:4133-4145

17. Lari GM, Dapsens PY, Scholz D, Mitchell S, Mondelli C, PérezRamírez J (2016) Deactivation mechanisms of tin-zeolites in biomass conversions. Green Chem 18:1249-1260

18. Padovan D, Tolborg S, Botti L, Taarning E, Sádaba I, Hammond C (2018) Overcoming catalyst deactivation during the continuous conversion of sugars to chemicals: maximising the performance of Sn-Beta with a little drop of water. React Chem Eng 3:155-163
19. Padovan D, Parsons C, Simplicio GM, Hammond C (2016) Intensification and deactivation of Sn-Beta investigated in the continuous regime. Green Chem 18:5041-5049

20. Tosi I, Riisager A, Taarning E, Jensen PR, Meier S (2018) Kinetic analysis of hexose conversion to methyl lactate by Sn-Beta: effects of substrate masking and of water. Catal Sci Technol 8:2137-2145

21. Padovan D, Botti L, Hammond C (2018) Active site hydration governs the stability of Sn-Beta during continuous glucose conversion. ACS Catal. https://doi.org/10.1021/acscatal.8b01759

22. Wolf P, Liao WC, Ong TC, Valla M, Harris JW, Gounder R, Van der Graaf WNP, Pidko EA, Hensen EJM, Ferrini P, Dikmans J, Sels B, Hermans I, Coperet C (2016) Identifying Sn site heterogeneities prevalent among Sn-Beta zeolites. Helv Chim Acta 99:916-927

23. Hammond C, Padovan D, Al-Nayili A, Wells PP, Gibson EK, Dimitratos N (2015) Identification of active and spectator Sn sites in Sn- $\beta$ following solid-state stannation, and consequences for Lewis acid catalysis. ChemCatChem 20:3322-3331

24. Hammond C, Conrad S, Hermans I (2012) Simple and scalable preaparation of highly active lewis acid Sn-Beta. Angew Chem Int Ed 52:11736-11739

25. Wolf P, Hammond C, Conrad S, Hermans I (2014) Post-synthetic preparation of $\mathrm{Sn}$-, Ti- and $\mathrm{Zr}$-Beta: a facile route to water tolerant, highly active Lewis acidic zeolites. Dalton Trans 43:4514-4519

26. Gunther WR, Michaelis VK, Caporini MA, Griffin RG, RomanLeshkov Y (2014) Dynamic nuclear polarizaion NMR enables the analysis of Sn-Beta zeolite prepared with natural abundance 119Sn precursors. J Am Chem Soc 136:6219-6222

27. Hwang SJ, Gounder R, Bhawe Y, Orazov M, Bermejo-Deval R, Davis ME (2015) Solid state NMR characterization of Sn-Beta zeolites that catalyse glucose isomerization and epimerization. Top Catal 58:435-440

28. Kolyagin YG, Yakimov AV, Tolborg S, Vennestrøm PNR, Ivanova II (2016) Application of 119Sn CPMG MAS NMR for fast characterization of Sn sites in zeolites with natural 119Sn isotope abundance. J Phys Chem Lett 7:1249-1253

29. Yakimov AV, Kolyagin YG, Tolborg S, Vennestrøm PNR, Ivanova II (2016) 119Sn MAS NMR study of the interaction of probe molecules with Sn-BEA: the origin of penta- and hexacoordinated tin formation. J Phys Chem C 120:28083-28092

30. Kolyagin YG, Yakimov AV, Tolborg S, Vennestrøm PNR, Ivanova II (2018) Direct observation of tin in different T-sites of Sn-BEA by 1D and 2D 119Sn MAS NMR Spectroscopy. J Phys Chem Lett 9:3738-3743

31. Wolf P, Valla M, Rossini AJ, Comas-Vives A, Nunez-Zarur F, Malaman B, Lesage A, Emsley L, Copéret C, Hermans I (2014) NMR Signatures of the active site in Sn-Beta zeolite. Angew Chem Int Ed 53:10179-10183

32. Wolf P, Valla M, Nunez-Zarur F, Comes-Vives A, Rossini AJ, Firth C, Kallas H, Lesage A, Emsley L, Copéret C, Hermans I (2016) Correlating synthetic methods, morphology, atomic-level structure, and catalytic activity of Sn-Beta catalysts. ACS Catal 6:4047-4063

33. Levenspiel O (1999) Chemical reaction, engineering. 3rd edn, ch. 21. Wiley, New York. p. 473

34. Gounder R, Davies ME (2013) Beyond shape selective catalysis with zeolites: hydrophobic void spaces in zeolites enable catalysis in liquid water. AIChE J 59:3349-3358

35. Gounder R, Davies ME (2013) Monosaccharide and disaccharide isomerization over Lewis acid sites in hydrophobic and hydrophilic molecular sieves. J Catal 308:176-188

36. Vega-Vila JC, Harris JW, Gounder R (2016) Controlled insertion of tin atoms into zeolite framework vacancies and consequences for glucose isomerization catalysis. J Catal 344:108-120

37. Conrad S, Wolf P, Múller P, Orsted H, Hermans I (2016) Influence of hydrophilicity on the $\mathrm{Sn} \beta$-catalyzed Baeyer-Villiger oxidation of cyclohexanone with aqueous hydrogen peroxide. ChemCatChem 9:175-182 
38. Gounder R, Davis ME (2013) Beyond shape selective catalysis with zeolites: hydrophobic void spaces in zeolites enable catalysis in liquid water. AIChE 59:3349-3358

39. Tolborg S, Katerinopoulou A, Falcone DD, Sádaba I, Osmundsen CM, Davis RJ, Taarning E, Fristrup P, Holm MS (2014)
Incorporation of tin affects crystallization, morphology, and crystal composition of Sn-Beta. J Mater Chem A 2:20252-20262 